\title{
A arte (en)cena: humanização \& loucura
}

The art (en)cena: humanization \& madness

El arte (en)cena: la humanización y desmadre

\section{César Gustavo Moraes Ramos}

Centro Universitário Luterano de Palmas, Palmas, TO, Brasil Irenides Teixeira

Centro Universitário Luterano de Palmas, Palmas, TO, Brasil Jonatha Rospide Nunes

Centro Universitário Luterano de Palmas, Palmas, TO, Brasil Mardônio Parente de Menezes

Centro Universitário Luterano de Palmas, Palmas, TO, Brasil Victor Meneses de Melo

Centro Universitário Luterano de Palmas, Palmas, TO, Brasil

\section{Resumo}

O portal “(En)Cena: a saúde mental em movimento”, lançado em 18/05/2011, é idealizado pelos cursos de Psicologia, Comunicação Social e Sistemas de Informação do CEULP/ULBRA, tem por objetivo intervir na cultura e divulgar material referente ao campo da saúde, em especial, o da Saúde Mental. Apesar de um tema específico, o portal abarca uma ampla gama de assuntos e experiências, visto que dessa temática subentende-se um conhecimento transdisciplinar que extrapola as disciplinas mais comumente a ela ligadas, abrindo espaço para além do campo da saúde. O (En)Cena possui nove seções que estimulam produções que ultrapassem a ordem técnicoacadêmica, incluindo, portanto, manifestações artístico-culturais originadas nos e relacionadas aos serviços de saúde. O portal (http://www.ulbra-to.br/encena) promove discussões de relevância social, fruto das práticas nas quais os colaboradores estão inseridos. O resultado se traduz em novos olhares e novas formas de pensar, de pesquisar, de ensinar e de atuar no campo da Saúde Mental que fomentam a transversalidade, o protagonismo e a tríplice inclusão; princípios esses estruturantes da Política Nacional de Humanização.

Palavras-chave: Arte, Cultura, Internet, Saúde Mental, Política Nacional de Humanização.

\section{Abstract}


The website "(En)Cena: a saúde mental em movimento", inaugurated on May 18, 2011, conceived by professors of Psychology, Social Communication and Information Systems of Centro Universitário Luterano de Palmas (CEULP/ULBRA), aims to act in culture and disclose material related to the field of Health, in particular to Mental Health field. Although it is devoted to a specific theme, the website covers a wide range of issues and experiences, since this theme requires a transdisciplinary knowledge, opening up a space beyond the boundaries of disciplines commonly related the field of health. The (En)Cena website consists of nine sections that stimulate productions that go beyond the academic matter and include cultural expressions that come from mental health services. The website (http://www.ulbra-to.br/encena) promotes socially relevant discussions, which are the result of practices in which collaborators are involved. The results are new perspectives and new ways of thinking, researching, teaching and acting in the field of Mental Health that promote mainstreaming, involvement and triple inclusion, principles that build the Política Nacional de Humanização.

Keywords: Art, Culture, Internet, Mental Health, Política Nacional de Humanização.

\section{Resumen}

El sitio web "(En) Cena: a saúde mental em movimento", concebido por profesores de Psicología, Comunicación Social y Sistemas de Información del Centro Universitario Luterano de Palmas (CEULP / ULBRA), inaugurado el 18 de mayo de 2011, tiene como objetivo actuar en la cultura y divulgar material relacionado con el campo de la salud, en particular com el campo de la Salud Mental. Aunque este espacio está dedicado a uno solo asunto, él cubre una amplia gama de temas y experiencias, ya que este tema requiere un conocimiento transdisciplinario, que abre un espacio más allá de los límites de las disciplinas comúnmente relacionadas con el campo de la salud. El sitio web (En)Cena consta de nueve secciones que estimulan producciones que van más allá de la cuestión académica e incluyen expresiones culturales procedentes de los servicios de salud mental. El sitio web (http://www.ulbra-to.br/encena) promueve discusiones de relevancia social, que son el resultado de prácticas en que sus colaboradores están insertados. Los resultados son nuevas perspectivas y nuevas formas de pensar, investigar, enseñar y actuar en el campo de la Salud Mental que promueven la integración, la participación y la inclusión triple, principios que conforman la Política Nacional de Humanização.

Palabras clave: arte, cultura, Internet, Salud Mental, Política Nacional de Humanização. 


\section{Introdução}

O “(En)Cena: a saúde mental em movimento" é, em sua primeira definição e de forma bastante geral, um espaço na web para o qual convergem produções artísticas que se traduzem em textos, imagens e áudios referentes ao tema da loucura. Contudo, além de ser um banco dessas produções o portal visa também estimulá-las, em especial no âmbito dos serviços de saúde, já que sua proposta partiu do pressuposto de que há muitas experiências vividas nesses serviços que condizem com a proposta da Reforma Psiquiátrica e da Luta Antimanicomial, mas que não são publicizadas. Tal pressuposto, baseado na experiência em serviços por parte dos idealizadores do portal, traduz uma deficiência do processo da Reforma Psiquiátrica, a saber: a dificuldade de modificar, no nível cultural, os preconceitos, os estigmas, as relações verticais presentes no modelo asilar de cuidado em saúde mental (Costa-Rosa, 2000). Dizendo de maneira mais direta, as experiências gestadas em serviços, na rede de atendimento em saúde, compõem um instrumento necessário para a mudança do modelo de atenção à saúde e, se não se transformam em cultura e conhecimento, perdem parte do potencial que possuem em produzir novas práticas.
Idealizado por professores e acadêmicos dos cursos de Psicologia, Comunicação Social e Sistemas de Informação do Centro Universitário Luterano de Palmas (CEULP/ULBRA), o (En)Cena conta com 13 acadêmicos voluntários e 10 docentes dos três cursos supracitados e já publicou mais de trezentos trabalhos de maio de 2011 a setembro de 2012 em suas nove seções: Cenas (seção com publicação de trabalhos imagéticos produzidos por acadêmicos, artistas e profissionais e usuários dos serviços de saúde, podendo ou não tais produções serem produtos de oficinas terapêuticas), Desterritorialize-se (seção destinada a textos de pessoas convidadas a produzir trabalhos sobre temas variados, não ligados a seus campos de conhecimento e que tragam a saúde mental como eixo transversal.), Em Cartaz (espaço destinado a resenhas, críticas e reflexões a respeito de obras - tais como: livros, filmes, exposições etc. - e eventos atuais que sejam relevantes para o tema da saúde mental), Entrevistas (seção destinada à divulgação de entrevistas feitas com pesquisadores, autores, gestores e especialistas em saúde, assim como as realizadas com usuários, familiares de usuários e profissionais de serviços de saúde mental, e que digam respeito ao tema de interesse do portal), Escritos (espaço que visa à publicação de narrativas 
que se deixam moldar em poesias, contos, crônicas, romances e narrativas), Insight (local reservado para textos teóricos, reflexões, críticas e comentários, de autoria da equipe do portal ou não, sobre temas contemporâneos que tragam a saúde mental como eixo transversal), Personagens (ambiente destinado a histórias de personagens, reais ou fictícios, pessoas ou instituições, que têm suas vidas e trajetórias relacionadas de alguma forma à saúde mental ou à loucura), Roteiros (seção onde se pode divulgar relatos de experiências ocorridas em serviços de saúde que, embora fujam do formato acadêmico tradicional, impõem-se por sua necessidade e por sua importância na produção do conhecimento relacionado à área), Trilhas (uma espécie de sarau musical sobre o passado, o presente e o "proto-futuro" da produção discursiva em Saúde Mental e onde se publicam fragmentos de sonoplastia textual datados, mas com reverberação atemporal, e interpretados-dublados sob a estética da peça radiofônica).

O (En)Cena, além de objetivar criar um espaço para ser ocupado por essas produções, objetiva também estimular as pessoas a transformar suas próprias vivências com a loucura em produtos (escritos, imagéticos e sonoros) que produzam movimento reflexivo, tanto no campo das idéias, dos conceitos, quanto no campo das relações que as pessoas fazem com aquilo que, ainda sem maiores definições, chamamos aqui de loucura. Desse modo, mais especificamente, o (En)Cena visa estimular os atores (pessoas que usam os serviços, profissionais e gestores) diretamente presentes nos serviços públicos de saúde, em especial os de saúde mental, a transformarem suas vivências nos já referidos produtos.

\section{Produto e Loucura como categorias}

É pertinente, a esta altura, deixar claro a que exatamente nos referimos quando usamos dois termos específicos: "produto" (escrito, imagético e sonoro) e "loucura". Quanto ao primeiro termo, cabe dizer que, de forma geral, o mundo é constituído por produtos escritos, imagéticos e sonoros que carregam consigo discursos. Dito de outra forma, tais produtos não se resumem apenas ao que representam, mas também pressupõem uma história de formação e, nas entrelinhas, uma comunicação de valores. Ademais, tais produtos, que dão continuidade a essa comunicação, quando presentes nas relações, produzem formas de as pessoas se relacionarem entre si e com o mundo. Dessa forma, entendemos que esta concepção parte do pressuposto de que este produto não necessariamente possui um fim em si mesmo, mas se 
desdobra em múltiplas possibilidades de conexão com o mundo.

A música é um produto, o livro e o artigo científico também, bem como o filme o é. Ao pensarmos sobre o cotidiano dos serviços de saúde, ainda bastante influenciados pelo modelo biomédicoasilar, chegamos à conclusão de que os produtos que medeiam as relações que ocorrem nesses serviços são, em sua maior parte, técnicos e burocráticos (Costa-Rosa, 2000). Podemos citar como exemplo disso os prontuários (quando usados como a principal fonte de comunicação), as fichas de atendimento, as práticas de cuidado verticais (que também carregam consigo uma história de formação bem como uma ideologia fortemente impregnada e impregnante) e o uso cada vez mais frequente de práticas (tanto farmacológicas, quanto sociais e psicoterapêuticas), que - quando usadas isoladamente como tratamento para a loucura - visam o mero tamponamento de sintomas. O próprio artigo pode ser considerado como um produto rígido, quando preza pelas regras e normatizações da Ciência que o elevam ao estatuto de “Artigo científico". Deleuze e Guattari (1997, vol. 5) destacam dois tipos de ciência: nômade e do Estado. Os autores enfatizam a diferença de formalização entre elas, enquanto a formalização nômade é a posteriori, constituída a partir do que o pesquisador vai encontrando pelo caminho; as formalizações da ciência do Estado são, a priori, definidas antes do encontro do pesquisador com o campo de pesquisa, ou seja, as regras são estabelecidas antes do processo de produção.

\begin{abstract}
É que as duas ciências diferem pelo modo de formalização, e a ciência de Estado não para de impor sua forma de soberania às invenções da ciência nômade; só retém da ciência nômade aquilo que pode apropriarse, e do resto faz um conjunto de receitas estritamente limitadas, sem estatuto verdadeiramente científico, ou simplesmente o reprime e o proíbe. (Deleuze \& Guattari, 1997, vol.5)
\end{abstract}

Assim sendo, o produto final carrega as marcas do processo pelo qual ele foi produzido, pelo qual uma multiplicidade de elementos heterogêneos se atravessam. Cada um desses elementos que aqui se chama de produto tem, pois, sua história pregressa e em criação, o que nos leva a uma importante categoria para as ciências sociais e para o paradigma que emergentemente vem questionando a produção atual do conhecimento: a categoria "processo".

Os processos se constituem como ações que resultam em produtos, que são modificados ao longo de um tempo e que se usam deles para reproduzir ou produzir 
práticas. Trata-se das ideias sendo operacionalizadas socialmente, trata-se de profusões sociais de ideias, trata-se portanto - de redes de relações nas quais necessariamente elementos afetivos, sociais, econômicos, simbólicos e de poder se evidenciam. Os processos aqui considerados não são estruturas escondidas a serem descobertas, mas, antes, a serem criadas, tendo em vista uma ética que tautologicamente (por que não assim o dizer - o conhecimento é tautológico) precisa dos próprios processos para se formar. De qualquer maneira, tais processos podem somente ser escritos (no sentido literal do termo) e inscritos (no sentido de tomarem existência corpórea) se deles forem cartografadas as linhas das relações entre as pessoas, alicerces da micropolítica de qualquer instituição. Podemos usar, nesse momento, outra categoria denominada processos de subjetivação para falar de tais relações. É por tal categoria que nos lançamos a falar sobre a loucura. Guattari (2009) afirma que o que chamamos de "eu", identidade, sujeito, é constituído a partir do cruzamento de uma multiplicidade de elementos heterogêneos e autônomos. Desta forma, fica em evidência a importância da diferença na produção subjetiva - pois é a partir da diferença que nos tornamos outros -, e da "loucura" como expressão radical desta diferença.
Outro pressuposto do qual parte a presente escrita é, portanto, o de que quando se fala em loucura se está falando em processos e não de um resultado. Tratase, contudo, de um processo indefinido, que tentamos tornar racional, mas que em todas as definições, seu caráter de indefinição aparece como fundamento. No demonismo, a fonte das manifestações, mesmo que nomeada como "demônio", tem como indefinida a forma de sua atuação; na Nau dos Loucos também, nos leprosos romanos, no inconsciente psicanalítico e no próprio conceito de doença fala-se de uma dimensão do homem para a qual não chegam as palavras: uma dimensão indefinida, portanto. David Cooper nos traz uma bela visão a respeito do discurso louco quando afirma que "A linguagem da loucura é o perpetuo deslizar das palavras para actos até se chegar o momento em que a palavra é puro acto" (1978, p.19).

Dizendo de outra maneira, a loucura é um dispositivo e o dispositivo para Deleuze é:

\footnotetext{
É antes de mais uma meada, um conjunto multilinear, composto por linhas de natureza diferente. E, no dispositivo, as linhas não delimitam ou envolvem sistemas homogêneos por sua própria conta, como o objecto, o sujeito, a linguagem, etc., mas seguem direções, traçam processos que estão sempre em
} 
desequilíbrio, e que ora se aproximam ora se afastam uma das outras. Qualquer linha pode ser quebrada - está sujeita a variações de direcção - e pode ser bifurcada, em forma de forquilha - está submetida a derivações. (Deleuze, 1997, p.1)

Não se pode negar que a definição acima de dispositivo pode muito bem ser usada para definir a psicose; pode também definir a produção artística ou a produção filosófica do livre pensar, da expressão aberta de opiniões dissonantes que nos permite convergir, divergir, misturar, nos aproximar e nos afastar. Esses processos: a psicose, a prisão, a arte, a filosofia e a liberdade de expressão foram historicamente ligados à loucura, todos eles tratados como tal, seja loucura ainda como manifestação transcendente, seja como manifestação de doenças.

O conceito de dispositivo apresenta também outros desdobramentos. Foucault (2006) utiliza-o para visualizar o conjunto/rede de processos heterogêneos de governabilidade proliferados em tempos de urgência, com função estratégica imersa em relações de forças que "condicionam certos tipos de saber e por eles são condicionados". Para Agambem (2009, p. 48) "aqueles que têm discursos similares, são de resto, o resultado do dispositivo midiático no qual estão capturados".
As oficinas terapêuticas são um exemplo disso: por elas, aposta-se numa vivência ético-estética e política diferente da vivência vertical entre são-louco, por meio da expressão artística, partindo da idéia de que a arte e a loucura conseguem se comunicar mais abertamente do que as técnicas profissionais o fazem em relação à doença. As oficinas terapêuticas, a depender logicamente dos seus processos, permitem ressaltar a diferença entre as pessoas, entre suas diversas formas de expressão e comunicação, ao mesmo tempo em que permite também construir formas de se relacionar diferentes das formas homogêneas da dita "normalidade" e de tamponamento, de coerção, de infantilização e vitimização, comuns às práticas profissionais em saúde. Permite, pois, tratar da loucura como uma vivência que, apesar de considerada estranha a costumes e expectativas ideológicas, é comum aos homens e às culturas, fonte de vida e criação (Lima \& Pelbart, 2007). Podemos perceber essa potência também nas sessões do Portal onde entramos em contato com produtos a respeito de "Loucos" trabalhando, trabalhadores se permitindo um momento de loucura, a produção artística e artesanal como terapêuticas e como possibilidade de sustentabilidade econômica, o trabalho formal com produtor de sofrimento, a família como lócus de produção de tristeza 
e alegria, a arte como produção inerente à vida e a vida como produção artística. Sem dúvida, estes elementos podem funcionar como analisadores ${ }^{1}$ que decompõe o discurso dominante disseminado pelo aparelho midiático.

A Reforma Psiquiátrica busca desmistificar e ampliar o debate sobre a relação que estabelecemos com a loucura. Para tanto, para se falar da loucura deve-se com ela conviver, relacionar-se. $\mathrm{O}$ resto que falamos sobre ela, quando com ela não se convive, é apenas repetição de palavras com ordem fraseológica, “...transmissão de palavra funcionando como palavra de ordem...", como diriam Deleuze e Guattari (1995, p.14). Portanto, para produzirmos novos discursos, nesse dispositivo chamado loucura, precisamos nos deixar viver com ela, seja lá como a definirmos; não basta apenas com ela conviver, mas também temos que criar múltiplas linguagens para falar do que é produzido em nós quando com ela nos encontramos.

Os produtos, engendrados nos encontros com a loucura, são meios de definição e as definições não são dadas apenas por conceitos duros; os diálogos também definem a loucura, os acordos, as práticas sociais, as festas, o uso de drogas, os esportes, a educação, a arte e o trabalho. Há definições duras e definições fluidas; as definições fluidas se constituem na vivência do afeto; as definições duras se constituem por imperativos, por prescrições, como as definições de doença mental; constituem-se apenas a partir de sua dimensão material, como produtos finalizados e não por processos; constituem-se por produtos que não disparam processos, mas, antes, (re)produzem relações alienadas e alienantes. A respeito disto, Deleuze e Guattari (1995) se referem a dois tipos de espaço (liso e estriado), a partir dos quais a realidade social é produzida.

\footnotetext{
O espaço liso e o espaço estriado, - o espaço nômade e o espaço sedentário, - o espaço onde se desenvolve a máquina de guerra e o espaço instituído pelo aparelho do estado, - não são da mesma natureza. (Deleuze \& Guattari, 1997, p. 179)
}

A vida do cidadão é aprisionada no fluxo de relações criado pelo Estado. Esse não é o único fluxo, mas é o que mais captura-regula nossos comportamentos, compondo assim o que se define por biopoder (Passos \& Benevides, 2001). A loucura possui um trânsito caótico demais para as expectativas de "ordem e progresso" que ainda espera o biopoder. Entendemos que a loucura tem sua gênese a partir de espaços lisos e que o Estado enquanto expressão máxima do espaço estriado - busca estratificar, classificar, normatizar a loucura. Por outro lado, a loucura enquanto processo não para de 
desestratificar, desconstruir, decompor o Estado. Dois movimentos importantes: um que vai do espaço liso dos fluxos afetivos que são capturados, tornados fixos, materializados; e outro que vai do espaço estriado das formas fixas que são dissolvidas, decompostas.

A loucura virou hoje uma instituição: institucionalizaram-na, ela institucionalizou-se. Toda instituição precisa de suas organizações para se materializar; as instituições são lógicas, as organizações, concretude; os equipamentos são tentáculos que buscam água; são raízes (Baremblit, 1998). Mas, nesses tentáculos, nesses equipamentos, há células que mudam ou tentam mudar a própria função da raiz em que se encontra. A Ética discute que raízes podem ou não se modificar funcionalmente e que funções adquirirão as que podem mudar, que valores mais se podem ou se devem produzir. Portanto, a Ética é o lócus para o qual se direcionam os aspectos instituintes das instituições. Por isso se diz de um paradigma ético emergente (Santos, 2006), pois questionar o biopoder é um exercício ético.

\section{As três apostas}

Para concluir e tentar arrematar esse tanto de ideias concatenadas, seguiremos o texto na defesa de três teses, abaixo escritas:
1) A loucura, enquanto dispositivo, produz múltiplas linguagens, ricas em sua diversidade. Assim sendo, trabalhamos com a publicização de linguagens diversificadas (escrita, sonora e imagética)

2) Os produtos escritos, sonoros e imagéticos são meios pelos quais as pessoas podem se relacionar com a loucura para além do discurso hegemônico, possibilitando uma diversidade de produções subjetivas;

3) O (En)Cena, além de banco de dados, é também um dispositivo de intervenção na cultura.

As duas primeiras teses não apresentam novidade. A Reforma Psiquiátrica e as clínicas do sujeito (as diversas abordagens psi), de maneira geral, têm enfatizado que a expressão, seja pela fala, pela arte, pelo corpo, é um meio terapêutico essencial para lidar com o sofrimento ligado à loucura. Contudo, o fato de publicizar, tornar público, reforça o caráter de atividade da expressão, pois ela passa a ser comentada, o que lhe permite protagonizar uma maior expressão política, que pode se tornar pública; todas elas, as expressões, miradas à existência, própria e coletiva. Todos nós nos relacionamos com a polis, mesmo em silêncio.

O (En)Cena visa possibilitar relações e dar visibilidade a linguagens outras, em especial àquelas que surgem na 
construção do vínculo entre pessoas que atuam nos serviços (seja lá de qual categoria faça parte), ou seja, àquelas em cujo seio está a convivência com a experiência da loucura. O (En)Cena quer modificar a luz que toca as cenas de cuidado em saúde mental, não por ser considerado, por seus idealizadores, um projeto iluminado. A luz de que aqui se fala não é a luz do Iluminismo, mas sim a luz que pretende clarear e tornar algo visível. Não é tudo que aparece quando uma luz é projetada e o visualizável é desvelado. Somente pelas sombras se vê o que reflete a luz. A medicina e a psicologia tradicionais têm se posto a ver, na loucura, sintomas. Pela força e status que possuem essas duas disciplinas, ao passo que vêem sintomas na loucura, os fazem ser vistos por demais disciplinas e pessoas. Criam uma forma de ver e, portanto, de lidar com a loucura (Rocha \& Deusdará, 2005) e reproduzem tal forma pelo aparato que possuem como os cursos de formação, os serviços de saúde e as propagandas.

A Reforma Psiquiátrica tem se preocupado em criar novas formas de lidar com a loucura. Nesse sentido, tem apostado na modificação daquilo que se vê; o que se vê, ao olhar-se para o sofrimento mental, não é um conjunto de sintomas, mas, antes, um processo de vida. Encarar a loucura como processo de vida é pressupor que, em tal vivência, há um tanto de coisas, ainda não faladas, ainda não vistas, que são atravessadas ao mesmo tempo em que constroem uma ética, afetos, economias e sociabilidades. Entendemos que o (En)Cena pode operar na dissolução das concepções de loucura, normalidade, doença mental, tratamento, etc; dentre outras concepções que permeiam a sociedade e as políticas públicas na saúde, em especial na saúde mental, possibilitando uma nova estratificação, ou seja, criando pontes através das quais o intituinte se torne instituído.

\section{Considerações finais}

Tendo em vista a discussão até aqui elaborada, chegamos a outro pressuposto fundante do (En)Cena que é o de que existe, nos serviços de saúde mental, uma gama de relações e experiências que fogem da instituição da loucura como doença e que não são vistas e nem delas se fala. $\mathrm{O}$ discurso, dentro dos próprios Centros de Atenção Psicossocial (os CAPS - um dos dispositivos nos quais aposta a Reforma Psiquiátrica) ainda se mantém hegemonicamente no formato "queixa", tanto no que o profissional escuta do usuário quanto no que o profissional diz sobre seu processo de trabalho. A queixa e os sintomas andam de mãos dadas; de um ao outro, a distância é apenas um tropeço. Assim, justifica-se o objetivo do (En)Cena, 
o que nos permite, agora, debruçarmo-nos sobre a terceira tese, a de que o (En)Cena é um dispositivo de intervenção na cultura, que promove estranhamentos, aproximações, alteridade e por conseguinte humanização.

Visto como um dispositivo, pela própria ideia que o originou, o (En)Cena tem provocado movimentos instituintes de caráter interdisciplinar. Tais movimentos têm provocado mudanças tanto no plano das relações daqueles que se propõem a colaborar com o portal quanto em um plano de ordem mais acadêmica e teórica. É por tal motivo que se pode afirmar que o (En)Cena é transversalizado pela interdisciplinaridade em pelo menos duas dimensões: em uma dimensão propriamente epistemológica e em uma outra dimensão que se diria de ordem vivencial e prática.

Como exemplo do primeiro caso, poderíamos citar a própria ideia de constituição do portal que, desde seu início, congregou - como antes mencionado - os cursos de Psicologia, de Comunicação Social e o curso de Sistemas de Informação. Tal composição do projeto aqui apresentado pode ser entendida a partir de sua característica básica: um espaço de comunicação virtual (demandando, assim, tanto a contribuição da Comunicação Social quanto da Informática) que pretende abordar o tema da saúde mental (interpelando, dessa forma, também a Psicologia). Contudo, a dimensão epistemológica não se esgota no mero encontro dessas três disciplinas, já que outras vieram se juntar ao debate ao longo da existência do portal. Dessa forma, contribuições de pessoas ligadas à Economia, Música, Psiquiatria, Administração, Artes, Matemática etc., todas discutindo saúde mental a partir de uma perspectiva integradora, têm sido cada vez mais comuns. Além disso, poder-se-ia incluir ainda na dimensão epistemológica, o próprio fato de o (En)Cena abordar a saúde mental a partir de uma lógica que visa questionar o próprio conceito de loucura e os discursos que sobre ela produzimos, incluindo discursos que $-\mathrm{de}$ outra forma - são delegados ao esquecimento da ciência tradicional. Assim, pode-se dizer que o portal é uma estratégia importante para se questionar o discurso sectário, separatista e monodisciplinar que a ciência hegemônica tem a respeito da loucura e que leva a uma visão estreita e míope da vivência de quem sofre psiquicamente.

No que toca a questão vivencial e prática, dimensão fundamental da interdisciplinaridade, o (En)Cena tem se constituído como campo de estágio e pesquisa para estudantes dos três cursos envolvidos. Ademais, o portal tem se dedicado ultimamente a coordenar 
atividades vivenciais tanto no espaço institucional em que foi gerado (portanto, na academia) quanto no próprio espaço vivo da cidade. Exemplo claro de ações dessa natureza foi a comemoração do Dia Nacional da Luta Antimanicomial, em maio de 2012. Tal evento foi denominado de "(En)Cena na praça: Saúde Mental se faz em Redes" e se caracterizou por convidar toda a comunidade da cidade para participar de uma tarde na praça, enquanto ocorriam oficinas diversas e redes de dormir eram atadas sob árvores para quem quisesse nelas deitar. A dimensão vivencial e pessoal é fundamental para que a interdisciplinaridade expanda seus efeitos para além dos textos acadêmicos e dos debates epistemológicos, já que ela “[...] não se efetiva por meio de princípios ou de intenções genéricas desenvolvidas em textos de pesquisadores bemintencionados" (Furtado, 2007, p. 247).

Outra parceria que redimensiona a processualidade do Encena é com a Política Nacional de Humanização (PNH), desenvolvida de dentro para fora do Ministério da Saúde. Por essa sua característica, e também por sua metodologia mais proeminente (a análise institucional em territórios de saúde), a PNH encontra-se numa posição entre a instância governamental e a popular, fazendo-as se comunicar. O portal de acesso HumanizaSUS, gerido por profissionais que trabalham na $\mathrm{PNH}$, apresenta trabalhos pioneiros de todos os estados brasileiros e com uma abrangência de milhares de acessos semanais. É, portanto, um rico e potente difusor de práticas antimanicomiais, antiburocráticas e democratizantes. A troca de logomarcas entre as redes de comunicação do HumanizaSUS e do (En)cena, com o intuito de se divulgarem, representa uma aproximação corpórea de resistência, de jeitos de fazer, de horizontes a alcançar, de olhares para a diversidade da vida, para a liberdade e dignidade do homem em um Estado Democrático de Direito.

Mas o que é o (En)cena? Um portal? Um agrupamento de pessoas impregnadas de/com a loucura? Um projeto acadêmico de extensão? Um campo/projeto interdisciplinar de pesquisa? Uma estratégia de Humanização? Utilizaremos a perspicácia de James Joyce ao se referir sobre a gestação de sua obra Finnegans Wake para dizer que o (En)Cena acima de tudo é um work in progress ${ }^{2}$, sendo assim (des)cobrir o (En)Cena é uma empreitada de cada protagonista.

\section{Notas}

1 Conceito da Análise Institucional fundamental para as estratégias da Política Nacional de Humanização que se refere a 
um acontecimento que explicita o jogo de forças institucional, a problematização daquilo que está naturalizado, o estranhamento como fomento a alteridade, a emergência dos conflitos como tencionadores coletivos de novos modos de vivenciar a produção em saúde.

2 Tradução: trabalho em andamento, conforme a introdução de Donaldo Schüler In: Joyce, James. Finnegans Wake/Finnicius Revém. Introdução, versão, notas Donaldo Schüler; desenhos Lena Bergstein. - 2 ed. - Cotia, SP: Ateliê Editorial, 2004. p. 25.

\section{Bibliografia}

Agamben, Giorgio. (2009). O que é contemporâneo? E outros ensaios. (V. Honesko, Trad.). Chapecó, SC: Argos.

Baremblitt, Gregório. (1998). Compêndio de análise institucional e outras correntes: teoria e pratica. $\left(4^{\mathrm{a}}\right.$ ed.). Rio de Janeiro: Record.

Cooper, David. (1978). A linguagem da loucura. Lisboa.

Costa-Rosa, Abilio. (2000). O modo psicossocial: um paradigma das praticas substitutivas ao modo asilar. In P. Amarante (Org.). Ensaios: subjetividade, saúde mental, sociedade. (pp.141-168). Rio de Janeiro: Fiocruz.
Deleuze, Gilles. (1997). Mistério de Ariadne segundo Nietzsche. In G. Deleuze. Crítica e clínica. São Paulo: Editora 34.

Deleuze, Gilles \& Guattari, Félix. (1995). Mil platôs: capitalismo e esquizofrenia. (Vol. 2). Rio de Janeiro: Ed. 34.

Deleuze, Gilles \& Guattari, Félix. (1997). Mil platôs: capitalismo e esquizofrenia. (Vol. 5). Rio de Janeiro: Ed. 34.

Guattari, Félix. (2009). As três ecologias. Campinas: Papirus.

Foucault, Michel. (2006). Ditos e escritos: ética, sexualidade, política. (Vol. 6). Rio de Janeiro: Forense Universitária.

Furtado, J. P. (2007). Equipes de referência: arranjo institucional para potencializar a colaboração entre disciplinas e profissões. Interface comunic, saúde, educ., 11(22), 239 255.

Joyce, James. (2004). Finnegans wake/finnicius revém. Introdução, versão, notas Donaldo Schüler; desenhos Lena Bergstein. (2 ed.). Cotia, SP: Ateliê Editorial.

Lima, Elizabeth Maria Freire de Araújo \& Pelbart, Peter Pál. (2007). Arte, clínica e loucura: um território em mutação. História, ciências, saúde- 
manguinhos, Rio de Janeiro, 14(3), 709-735, jul.-set.

Passos, Eduardo \& Benevides, Regina. (2001). Clínica e biopolítica na experiência do contemporâneo, Psicologia Clínica, 13(1), 89-99.

Rocha, D. \& Deusdará, B. (2005). Análise de conteúdo e análise do discurso: aproximações e afastamentos na (re)construção de uma trajetória. Alea, 7(2), 305-322, jul-dez.

Santos, B. S. (2006). Um discurso sobre as ciências. (4a Ed.). São Paulo: Cortez.

\section{César Gustavo Moraes Ramos:}

Psicólogo com mestrado em Ciências Criminais (PUC/RS). Professor e

Coordenador do curso de Psicologia do Centro Universitário Luterano de Palmas CEULP/ULBRA.

E-mail: cgmramos@gmail.com

Irenides Teixeira: Psicóloga, graduada em Publicidade e Propaganda e em Processamento de Dados com mestrado em Comunicação e Mercado (FACASPER/SP). Professora dos cursos de Comunicação Social e de Psicologia do Centro Universitário Luterano de Palmas CEULP/ULBRA.

E-mail: irenides@gmail.com

Jonatha Rospide Nunes: Psicólogo com mestrado em Psicologia Social (UFF/RJ) Professor do curso de Psicologia do Centro
Universitário Luterano de Palmas CEULP/ULBRA.

E-mail:

jonatharospidenunes@yahoo.com.br

\section{Mardônio Parente de Menezes:}

Psiquiatra com mestrado em Psicologia (UNESP/ASSIS-SP). Professor do curso de Psicologia do Centro Universitário Luterano de Palmas - CEULP/ULBRA.

E-mail: mardonioparente@gmail.com

Victor Meneses de Melo: Psicólogo com mestrado em Psicologia (UNESP/ASSISSP). Professor do curso de Psicologia do Centro Universitário Luterano de Palmas CEULP/ULBRA.

E-mail: victormelo@yahoo.com.br 